\title{
A RESPONSIVIDADE EM UM CURSO DE FORMAÇÃO CONTINUADA DOCENTE
}

\section{The Responsiveness in a Teachers' Continuous Development Course}

\author{
Marilúcia dos Santos Domingos STRIQUER, UENP ${ }^{1}$
}

\begin{abstract}
RESUMO: Este artigo tem como objetivo investigar quais os níveis de responsividade que se estabelecem nos participantes do Grupo de Trabalho em Rede, que é um curso de formação para docentes do estado do Paraná, uma vez que a responsividade é um elemento constitutivo do dialogismo. Os resultados demonstram que o que fazem os cursistas é apenas responder imediata e silenciosamente as etapas do curso, reproduzindo discursos alheios.
\end{abstract}

PALAVRAS-CHAVE: Responsividade; Formação de professores; Formação continuada docente.

ABSTRACT: This paper aims to investigate which responsiveness levels are established by the participants in the Working Group Network, which is a teacher's continuous development course for the state of Paraná, since the responsiveness is a constituent element of dialogism. The results show that what the course participants do is only to respond immediately and silently to the stages of the course, reproducing other people's discourses.

KEYWORDS: Responsiveness; Teacher Development; Teachers' Continuous Development Course

\section{INTRODUÇÃO}

Norteado pelas teorias bakhtinianas, ${ }^{2}$ este trabalho tem como objetivo refletir se um curso de formação continuada docente cumpre seu papel fundador de ferramenta de

\footnotetext{
${ }^{1}$ Doutora em Estudos da Linguagem pela Universidade Estadual do Norte do Paraná (UEL). Professora da Universidade Estadual do Norte do Paraná (UENP), campus Jacarezinho. marilucia@uenp.edu.br

2 Ao tomar como base teórica os preceitos da obra "Estética da criação verbal" de Bakhtin (2003) e da obra "Marxismo e Filosofia da Linguagem" de Bakhtin/Volochinov (2006) faço a opção de referenciar os autores catalogados nas edições consultadas, não me ocupando, portanto, neste artigo, em tomar um posicionamento frente à questão da "problemática dos textos disputados" (BRONCKART; BOTA, 2012). Tal problemática, já por décadas discutida, foi trazida, novamente, à discussão pela obra "Bakhtin desmascarado: história de um mentiroso, de uma fraude, de um delírio coletivo" (BRONCKART; BOTA, 2012), onde os autores defendem que, por exemplo, Volochinov é o autor de "Marxismo e filosofia da Linguagem", bem como do artigo "Os gêneros do discurso" constante da obra "Estética da criação verbal", atribuindo a caracterização de mentirosa a afirmativa bakhtiniana que estes textos eram de autoria dele. Em pesquisa e aprofundados estudos, Bronckart; Bota (2012, p. 18) defendem a derrubada da "tese da onipaternidade bakhtiniana" (em que Bakhtin é apresentado como sendo o autor da maioria dos escritos de
} 
aprimoramento e desenvolvimento do professor para que este, cada vez mais, tenha condições de atuar e intervir no sistema educacional. Nossa premissa é a de que, em um processo formativo, o professor em formação não apenas compreende a cultura, os conhecimentos científicos, os conteúdos escolares, as práticas pedagógicas abordadas durante o curso do qual participa, mas tem "uma atitude responsiva ativa" (BAKHTIN, 2003). Ou seja, espera-se que o professor em formação possa completar, adaptar, transformar o que foi enunciado durante o processo formativo, visto que, de acordo com Bakhtin (2003, p. 271), "toda compreensão é prenhe de resposta". Enfim, espera-se que o professor reaja de alguma forma aos enunciados proferidos pelos formadores, pois a responsividade é um elemento constitutivo do dialogismo. É a responsividade que permite que o diálogo continue, seja interrompido ou postergado de alguma forma (MENEGASSI, 2008).

Desta forma, responder ativamente não é reproduzir o que foi debatido, estudado e conhecido durante a participação de um professor em um curso de formação porque

Quando a atividade mental se realiza sob a forma de uma enunciação, a orientação social à qual ela se submete adquire maior complexidade graças à exigência de adaptação ao contexto social imediato do ato de fala, e, acima de tudo, aos interlocutores concretos. (BAKHTIN/ VOLOCHINOV, 2006, p. 120).

Portanto, responder ativamente é um processo de adaptação, de recriação, de transformação do que foi abordado diante de um contexto social imediato, no caso dos professores, diante de suas salas de aula, de interlocutores concretos com os alunos, os pares, a comunidade escolar, a secretaria de educação, a sociedade. A responsividade ativa ocorre, de acordo ainda com Bakhtin/Volochinov (2006), porque toda forma de expressão é determinada pelo conjunto social em que o locutor convive, uma vez que “exteriorizando-se, o conteúdo interior muda de aspecto, pois é obrigado a apropriar-se do material exterior, que dispõe de suas próprias regras, estranhas ao pensamento interior" (BAKHTIN/VOLOCHINOV, 2006, p. 113).

Dessa forma, o objetivo deste artigo é investigar quais os níveis de responsividade se estabelecem nos cursistas participantes do Grupo de Trabalho em Rede (GTR), um curso de formação para docentes da rede estadual de ensino do estado do Paraná integrado

Voloshinov e de uma obra de Medvedev “O método formal nos estudos literários”), na intenção de creditar cada obra a seu legítimo autor. 
a um programa maior da Secretaria Estadual de Educação do Paraná (SEED), o Programa de Desenvolvimento da Educação (doravante PDE).

\section{O GRUPO DE TRABALHO EM REDE (GTR)}

O GTR é uma das atividades integrantes do PDE, o maior programa de formação de professores em serviço do estado do Paraná. Com duração de dois anos e carga horária total de 952 horas, o PDE é, desde 2007, uma proposta que proporciona progressões na carreira docente e melhoria na qualidade da educação do estado. Ao participar deste programa, o professor, denominado de professor PDE, tem uma série de atividades a serem cumpridas, as quais se enquadram em três eixos: o eixo I- Atividades de Integração teórico-práticas: o professor PDE produz: um Projeto de Intervenção Pedagógica na escola; um material didático para auxiliá-lo na implementação do Projeto; um artigo científico, produzido ao final da implementação para relatar todo o processo vivenciado no programa. Ele também participa de encontros acadêmicos sob orientação de um professor de uma instituição de ensino superior, o qual acompanha todas as atividades. $\mathrm{O}$ eixo II - Atividades de aprofundamento teórico: contemplam a participação em cursos sobre fundamentos da educação, de políticas curriculares, de gestão, de financiamento da educação básica e em metodologia da pesquisa científica; participação em seminários de integração; em oficinas para a educação digital; em congressos, colóquios, eventos promovidos pelas IES. E, o eixo III- Atividades didático-pedagógicas, é o eixo do Grupo de trabalho em Rede- GTR, que abrange a interação virtual entre professores PDE e demais professores da rede de ensino, no qual participantes do GTR passam a ser denominados de cursistas. De forma mais específica, a proposta é que, a partir dos conhecimentos apreendidos/aprimorados durante a participação do professor no PDE, ele (obrigatoriamente) organize um grupo formado por professores da rede pública de ensino, a fim de socializar o que ele apreendeu/aprimorou no PDE com os professores da rede (cursistas).

De acordo com a SEED, ${ }^{3}$ os objetivos gerais do GTR são:

\footnotetext{
${ }^{3}$ Toda regulamentação, instrução e definição do GTR é disponibilizada pela Secretaria de Educação do Estado do Paraná, por meio da coordenação do PDE no site da Secretaria. Disponível em: http://www.educadores.diaadia.pr.gov.br/modules/conteudo/conteudo.php Acesso em 30/01/2012.
} 
- possibilitar novas alternativas de formação continuada para os professores da Rede Pública Estadual;

- viabilizar mais um espaço de estudo e discussão sobre as especificidades da realidade escolar;

- incentivar o aprofundamento teórico-metodológico, nas áreas de conhecimento, através da troca de ideias e experiências sobre as áreas curriculares;

- socializar o Projeto de Intervenção Pedagógica na Escola elaborado pelo professor PDE com os demais professores da Rede

O professor PDE é o tutor de seu grupo que recebeu formação específica nas oficinas de educação digital do programa e em uma oficina sobre a dinâmica do GTR. Ele pode propôr apenas um GTR durante sua participação no PDE e todas as atividades são realizadas à distância, pelo sítio www.diaadia.pr.gov.br.

O professor cursista, quando participa de um GTR com duração de 6 meses, recebe certificado de 64 horas e 6 pontos para avanço bienal do Plano de Cargos e Salários do Paraná, além de poder participar da seleção anual para ingresso no PDE.

\section{RESPONSIVIDADE}

Baseado nos pressupostos bakhtinianos e em sua afirmativa de que o nível de responsividade é variável, Menegassi (2009) distingue três níveis de manifestação da responsividade: a responsividade imediata, a silenciosa e a retardada.

A responsividade imediata é quando, logo após ouvir/ler um discurso, o interlocutor materializa uma resposta de alguma forma, que pode ser em um ato fônico, manuscrito, gestual, ou até mesmo por meio de expressões faciais. É uma devolutiva imediata, o que não significa, segundo Menegassi (2009, p. 160), relação de tempo, de cronologia, "é uma atitude responsiva certa, determinada, imediata à provocação do locutor".

O segundo nível, a atitude responsiva silenciosa, está ligado "a execução da ordem compreendida e acatada" (MENEGASSI, 2009, p. 272). É uma devolutiva que não requer necessariamente a verbalização oral ou escrita da resposta, pois é mais um atendimento e cumprimento de um pedido, solicitação ou ordem construídos em uma "relação social altamente assimétrica, autoritária na relação entre falante e ouvinte" ou em situações institucionalizadas “em que o enunciado se articula de forma que não reste ao destinatário da palavra outra possibilidade que não seja o cumprimento fiel e silencioso do que lhe foi solicitado" (MENEGASSI, 2009, p. 163). 
Um outro aspecto que também caracteriza a responsividade silenciosa é a "necessidade de compreensão mais abstrata, de reelaboração mental" (MENEGASSI, 2008, p. 137), por isso, não imediata. O interlocutor precisa de um tempo maior para a abstração do discurso do outro para reelaboração de sua resposta. Este tipo de resposta está presente mais constantemente na produção escrita. Após refletir sobre leituras, debates, comentários, opiniões e notícias, o indivíduo reflete, seleciona, organiza seu discurso e elabora seu texto-resposta em um tempo que, muitas vezes, não é considerado pela escola. Logo após o trabalho com a leitura de um texto, pede-se que o aluno produza um texto escrito e, geralmente, que o produza, respondendo ao discurso anterior, dentro do tempo padrão da aula.

Já a atitude responsiva de ação retardada difere-se das outras duas por ser "uma materialização de efeito retardado da resposta inerente a um determinado enunciado" (MENEGASSI, 2009, p. 165). Esse tipo de resposta acontece quando o interlocutor, após ouvir/ler um discurso, não o responde imediatamente. Nesse caso, a resposta fica, por um tempo, curto ou longo, "temporalmente deslocada da situação real, contudo, ela é perceptível nos discursos subsequentes do parceiro da comunicação, em situações comunicativas diversas daquela que lhe deu origem" (MENEGASSI, 2008, p.139). O efeito retardado acontece, muitas vezes, pela própria natureza da enunciação, que não exige uma manifestação imediata, a qual se materializa de forma verbal ou por meio de comportamentos.

Além desses três níveis, Menegassi (2008), em estudos sobre a escrita produzida por alunos do ensino superior, chegou a outros dois níveis que são manifestações dos primeiros: a) A resposta ativa - quando, depois de manifestar uma resposta silenciosa, o indivíduo manifesta a de efeito retardado ampliando-a com a apresentação de argumentos, mas sem exposição de reflexões pessoais; b) A resposta ativa e crítica - ocorre o mesmo que na ativa, porém com a apresentação de argumentos, de explicações e exemplos formados de acordo com os julgamentos e avaliações pessoais feitas pelo indivíduo.

Sobre esses conceitos, Menegassi (2009) destaca ainda que as respostas podem ser tanto para o outro, uma outra pessoa, quanto para o outro de si mesmo, a própria pessoa. Em qualquer um dos casos, a responsividade é "resultado da internalização e da reconstrução das práticas sociais das quais o sujeito toma parte ao longo de sua existência" (MENEGASSI, 2009, p. 152).

\section{A RESPONSIVIDADE INSTITUIIDA NO GTR}


O GTR do qual participaram as oito professoras cursistas analisadas foi tutoriado por uma professora PDE da turma de 2009, denominada ficticiamente de Paula, e aconteceu durante o segundo período da participação da mesma no programa, entre fevereiro a julho de 2010.

O GTR para a turma de 2009 subdividiu-se em cinco unidades de trabalho:

Unidade 1 - Apresentação da professora PDE no GTR; postagem de sua proposta de estudo e de um esboço de seu Projeto de Intervenção na Escola. Inscrição e apresentação dos professores cursistas.

Unidade 2 - Debate sobre questões relacionadas à Educação a Distância.

Unidade 3 - a) a tutora apresenta um texto teórico para leitura e debate entre os participantes por meio de Fóruns; b) a partir do texto do Fórum, a tutora elabora questões de reflexão mais voltadas à prática de ensino, referente à teoria em debate, e os cursistas interagem a partir de um Diário produzidos por eles; c) A última atividade da Unidade é chamada de Tarefa: sobre a teoria em estudo, os cursistas produzem um texto teórico.

Unidade 4 - A tutora posta no sistema a fundamentação teórica e os encaminhamentos metodológicos de seu Projeto de Intervenção para que os cursistas interajam, conforme especificado nos Fóruns e Diários.

Unidade 5 - Em um primeiro momento, é postada a seção de Estratégia de ação do Projeto de Intervenção da tutora para debate no Fórum e no Diário e, em seguida, a tutora posta também o seu Material didático-pedagógico (outra atividade obrigatória produzida pelo professor PDE) para o mesmo procedimento.

Selecionei para esta presente investigação apenas a Unidade 3 do GTR de Paula, uma vez que a Unidade 1 era apenas de apresentação dos participantes e a Unidade 2 discutia a educação à distância, ou seja, não debatia conteúdos da disciplina propriamente dita dos professores participantes do grupo. E, principalmente, justifico a escolha porque o que ocorreu na Unidade 3 representa de forma fiel os acontecimentos das Unidades 4 e 5.

Inscreveram-se para este GTR oito professoras, conforme mencionado, para as quais Paula, na Unidade 3, propôs a discussão do capítulo Os gêneros do discurso do livro Introdução ao pensamento de Bakhtin (FIORIN, 2006), postando em seu Fórum de discussão o seguinte texto: 
"Neste fórum de discussões iremos compartilhar experiências, assim como refletir sobre o texto: Os gêneros do discurso, de José Luiz Fiorin, disponível no box da Unidade 2, Material Didático/Textos Complementares. Após a leitura, responda as seguintes questões, justificando-as: 1. É possível ensinar os gêneros do discurso na escola? Justifique sua resposta. 2. É papel da escola trabalhar com gêneros do discurso ou a ela só caberia o trabalho mais pontual com textos de diferentes modalidades: narrativa, argumentativa, expositiva? Justifique. 3. Como as DCE de Língua Portuguesa orientam o trabalho com os gêneros do discurso na escola?".

As respostas de duas professores cursistas, transcritas a seguir, foram classificadas no nível da responsividade imediata, uma vez que são devolutivas imediatas do que foi postado pela tutora, e, principalmente, são respostas silenciosas no sentido de que cumprem a situação impostas pelo GTR. Por terem ficado completamente presas ao enunciado de Paula, sem ampliações do texto de referência e de exposição de justificativas, como solicitou a tutora, as duas respostas não alcançaram o nível de uma responsivilidade ativa e crítica, podendo ser interpretadas como o início da etapa da compreensão que, de acordo com Bakhtin (2003), é a primeira fase do processo de responsividade. Exemplos:

Fórum - exemplo 1: "Os gêneros do discurso podem ser ensinados na escola, pois os nossos alunos diariamente estão em contato com estes gêneros. O mundo atual incorporou da cultura eletrônica diversos tipos de gêneros onde os alunos tem contato com os mesmos principalmente através da internet. As diretrizes curriculares orientam que é necessário que a inclusão da diversidade textual possa relacionar os gêneros com as atividades sociais em que eles se constituem".

Fórum - exemplo 2: “As DCE's trazem um trabalho bem claro no que diz respeito aos gêneros discursivos, isso se evidencia através do conteúdo estruturante: o discurso como prática social. Essas diretrizes orientam que o trabalho com a língua deve ser pautado nos diversos gêneros textuais praticados pelos alunos e na sociedade em geral".

Na participação, na reflexão, na seleção, na organização de seu discurso no Fórum, o professor cursista deveria elaborar seu discurso/resposta baseado em argumentos, explicações e exemplos, de acordo com julgamentos e avaliações pessoais e, assim, responderia ativa e criticamente aos discursos proferidos no GTR. As respostas ativas e críticas (MENEGASSI, 2009) eram esperadas pela professora-tutora e também a proposta da interação/do GTR, mas isto não ocorreu nestas duas respostas. Além disso, o mesmo acontece nas outras três respostas dadas por outras cursistas no Fórum. Pela maneira como as outras três respostas se constituíram, elas também são apenas cumprimento da 
obrigatoriedade da participação das professoras no GTR, visto que são respostas totalmente evasivas:

Fórum - exemplo 3: "Em respostas à questão sobre gêneros tenho a convicção que estão de acordo com a opinião demonstrada pela participante, pois as referências são semelhantes".

Fórum - exemplo 4: "Concordo com sua opinião, acho que os gêneros discursivos são pertinentes e adequados para o trabalho em sala de aula. Eles tornam nossas atividades interessantes e motivadoras para os alunos".

Fórum - exemplo 5: "Seu texto está completo e claro, vale lembrar sempre a importância de diversificar os gêneros, acrescentando conhecimento ao discurso do aluno e capacitando-o para o social. Bom trabalho!"”.

Portanto, diante do modo de participação das cursistas, elas não respondem ativamente a enunciação: não há compartilhamento de experiências; não há relação direta das resposta com o texto de Fiorin; as respostas estão presas apenas as perguntas; as cursistas não apresentam justificativas; algumas das respostas nem mesmo fazem referência a DCE, não respondendo a terceira pergunta elaborada por Paula. Dessa forma, a possibilidade de aprofundamento dos estudos teóricos-metodológicos por meio da troca de ideias e experiências, isto é, a construção da responsividade em nível ativo e crítico (MENEGASSI, 2008, 2009), conforme os objetivos propostos no GTR, não foi cumprida no Fórum. Embora fosse o momento mais propício para o alcance desse objetivo, a forma pela qual as cursistas responderam mostra que esta responsividade não aconteceu.

A participação das cursistas no Fórum demonstra que não houve aprofundamento teórico por parte delas na referida atividade. Não há nenhuma menção, citação, paráfrase ou crítica ao texto teórico, causando a impressão de que as mesmas nem ao menos estudaram o texto de referência; simplesmente responderam as perguntas considerando alguns conhecimentos sobre o assunto que elas já tinham e o enunciado elaborado por Paula.

O mesmo acontece na atividade de produção do Diário. Para que as cursistas produzissem seus Diários, Paula postou a seguinte questão:

\footnotetext{
"No trabalho em sala de aula, como explorar os três elementos que Bakhtin apontou como componentes integrantes e indissociáveis de cada gênero (conteúdo temático, construção composicional e ato estilístico) de forma a contemplá-los coerentemente, sem privilegiar um em detrimento do outro?".
}

Relembrando o objetivo do Diário: a partir do texto do Fórum, a tutora elabora questões de reflexão mais voltadas à prática de ensino, referente à teoria em debate, e os 
cursistas, por sua vez, interagem a partir de um Diário produzidos por eles. Contudo, os resultados das análises mostram que, mais uma vez, cinco das oito respostas totais, ficaram presas ao enunciado produzido por Paula, sem exposição de como a teoria se relaciona à prática de sala de aula. Exemplo:

Diário - exemplo 1: "No trabalho em sala de aula deve-se levar em conta os 3 elementos indissociáveis de cada gênero (conteúdo temático, estilo e construção composicional) para que haja condições específicas e finalidades.

Segundo as Diretrizes Curriculares (2006) 'cabe ao professor que além do contato com diferentes textos deve-se propiciar que o aluno expresse sua análise por meio dos diferentes gêneros, considerada a sua criatividade. Antes dessa etapa, no nível oral e escrito, está a interpretação que faz proliferar o pensamento, que abre a possibilidade de o aluno jogar, criar, atualizar os gêneros'.

Ao trabalhar em sala de aula com os gêneros textuais selecionados é interessante que $\mathrm{o}$ aluno tenha contato com diversos textos do mesmo gênero para que conheça como o mesmo é construído, após o professor pode explicar como ele é construído levando em conta o conteúdo temático, o estilo e a construção composicional, a partir disso construir o seu. Para Fiorin "A aprendizagem dos modos sociais de fazer leva, concomitantemente ao aprendizado dos modos sociais de dizer, os gêneros".

O texto resposta do Diário-exemplo 1 apenas faz paráfrase em seu primeiro e terceiro parágrafos do enunciado de Paula, e o segundo parágrafo é constituído de uma citação das Diretrizes Curriculares do Estado do Paraná (DCE) (PARANÁ, 2009). Isto é, a cursista, ao responder à questão, não revela se a teoria e/ou como a teoria pode ser transposta para a sua prática de sala de aula. A resposta é apenas uma reprodução do discurso alheio, do enunciado produzido por Paula, das diretrizes e do texto de Fiorin.

Outras duas respostas demonstram um agravante maior do que não cumprirem a proposta do Diário, elas se constituem de plágios:

Diário - exemplo 2: "Em uma situação de interação típica da comunicação discursiva de determinada esfera social, a escolha do gênero não é inteiramente espontânea, pois considera um conjunto de restrições dadas pela própria situação de interação verbal: quem fala, sobre o que fala, com quem fala, como fala, com qual finalidade. Todos esses elementos determinam as escolhas do locutor, que, tendo ou não consciência, decide utilizar o gênero mais adequado àquela situação.

Esses elementos compõem gêneros discursivos caracterizados por três dimensões essenciais indissociáveis: o tema, a forma composicional e o estilo.

Como muito bem salientou Bakhtin ([1952-53] 2003), os modelos comunicativos servem para criar uma expectativa no interlocutor e prepará-lo para uma determinada reação ou compreensão ativa e consciente pela apreensão de significados ajustados à realidade do sujeito, com o objetivo de transformá-la histórica e socialmente.

Todos devem compreender a forma como linguagem e ideologia se articulam e se afetam em sua relação recíproca na produção de sentido gerado nos discursos. [...]".

Essa resposta do Diário-exemplo 2 é uma cópia fiel de um trecho do artigo “Gêneros discursivos: objetos de estudo para a prática escolar de produção escrita de 
textos jornalísticos" de Adriana Socorro, publicado no sitio: http://alb.com.br/arquivomorto/edicoes_anteriores/anais16/sem11pdf/sm11ss03_02.pdf. Isto é, a professora cursista não indica a fonte de seu texto, o toma como se fosse seu. Situação similar ocorre com uma outra cursista: sua resposta é uma cópia fiel de um projeto intitulado "Gêneros textuais: tirando de letra" publicado no sitio: http://pitadasdesaber.blogspot.com/2010/03/projeto-generos-textuais-tirando-de.html.

Destaco aqui o fato de que o professor PDE, ao participar dos cursos de metodologia da pesquisa científica (eixo II de atividades), recebe toda a orientação sobre construção do texto acadêmico e sobre direitos autorais, sendo este último é tema de uma oficina específica ${ }^{4}$.

Considero que o que ocorreu nas respostas dos Diários das duas cursistas que plagiaram textos e das outras cinco, as quais ficaram presas ao texto teórico de referência, foi totalmente condizente com o que aconteceu nos fóruns: há apenas uma resposta de obrigatoriedade pela participação no GTR, mas não há cumprimento da atividade de relacionar a teoria em questão com a prática de sala de aula das cursistas. Nenhuma das 8 cursistas fez referência a sua própria prática de sala de aula em seus Diários.

No que se refere à Tarefa, que visa a produção de um texto teórico a partir da perspectiva em estudo na Unidade 3, as atividades-tarefas são realizadas cumprindo as regras de participação no GTR, isto é, novamente, respondem imediatamente e silenciosamente ao solicitado. No entanto, os textos-Tarefas são cópias dos textos pesquisados pelas cursistas. Ao analisar os textos-Tarefas e as referências bibliográficas que anunciaram quais textos foram pesquisados pelas cursistas, ficou evidente que seus discurso eram apenas repetições dos discursos alheios (dos autores dos textos de referência). Por exemplo, o texto de uma das cursistas tem cópia de trechos inteiros do artigo "Os gêneros do discurso e o texto escrito na sala de aula: uma contribuição ao ensino" de Maria Angélica Freire de Carvalho, publicada no sítio: http://www.filologia.org.br ${ }^{5}$. O mesmo acontece com o texto de uma outra cursista que faz cópias de trechos inteiros do artigo "Os gêneros do discurso e o ensino da Língua

\footnotetext{
${ }^{4}$ Toda estrutura e cronograma de cursos, orientação, eventos é disponibilizada pela Secretaria de Educação do Estado do Paraná, por meio da coordenação do PDE no site da Secretaria. Disponível em: http://www.educadores.diaadia.pr.gov.br. Acesso em 30/01/2012.

${ }^{5}$ Fonte completa: Disponível em: http://www.filologia.org.br/ vicnlf/anais/os\%20generos.html. Acesso em $10 / 05 / 2014$
} 
Portuguesa" de Maria Sílvia Cintra Martins, publicado no site: http://www.letramento.iel.unicamp.br ${ }^{6}$.

Portanto, as cursistas produzem, de fato, um texto teórico. Todavia, este não responde ativa e criticamente a proposta da formação no GTR.

\section{CONSIDERAÇÕES FINAIS}

As análises das interações que aconteceram no Fórum, no Diário e na Tarefa da Unidade 3 do GTR de Paula demonstram que os níveis de responsividade que se estabelecem nas cursistas participantes é o imediato e o silencioso, visto que seus textosrespostas não completam, nem adaptam ou transformam o que foi enunciado pela tutora e pelos teóricos em pauta no GTR. Existe apenas reprodução de discursos alheios.

Em decorrência da prática estabelecida pelas cursistas, o GTR de Paula, a priori, não cumpriu seu papel fundador de ferramenta de aprimoramento e desenvolvimento do professor em formação. De acordo com os objetivos estabelecidos pela SEED, o GTR de Paula possibilita novas alternativas de formação continuada para os professores cursistas; viabiliza um espaço de estudo e discussão; incentiva o aprofundamento teóricometodológico; socializa as produções. Portanto, Paula cumpre todas as regulamentações para a construção de seu curso. Porém, seu GTR não se constitui como ferramenta porque os interlocutores da interação não realizam a contraparte: não há discussão sobre as especificidades da realidade escolar, os cursistas não expõem suas próprias práticas e experiências em nenhum dos momentos solicitados; ao ficarem presos nos discursos alheios, não há também demonstração de aprofundamento teórico-metodológico.

Evidentemente, muitos fatores concorrem para que o GTR em questão tenha se constituído da forma como se revelou. Desta forma, destaco apenas um dos motivos: a participação do professor em, pelo menos um GTR, permite o ingresso do mesmo no PDE, única maneira deste docente da rede pública de ensino do estado do Paraná alcançar o último nível da carreira do quadro próprio do magistério do estado. Em outras palavras, a participação em um GTR é uma obrigatoriedade para que os professores ingressem no PDE e, consequentemente, alcancem o último nível no Plano de Cargos do Estado do Paraná. Assim, os cursistas participaram do GTR de Paula, mas não o tomaram como uma

\footnotetext{
${ }^{6}$ Fonte completa: Disponível em: http://www.letramento.iel.unicamp.br/publicacoes/artigos/Generos do discurso ensino.pdf. Acesso em: 10/05/2014.
} 
ferramenta de formação docente, apenas cumpriram uma obrigatoriedade para ascenderem nas carreiras.

Contudo, é válido expôr que a responsividade em nível ativo e crítico, por vezes, pode se constituir em momento deslocado do enunciado: as cursistas participantes do GTR de Paula podem, em um outro momento, depois de já concluído todo o processo de formação no GTR, refletir a respeito dos textos estudados, organizar seus julgamentos e avaliações pessoais a respeito, e, então, responder ativa e criticamente aos discursos proferidos na formação continuada, em suas salas de aula. Isto seria o resultado da internalização que, de acordo com Vygotsky (2007), ocorre depois de uma longa série de eventos, e, conforme Menegassi (2009), representaria a reconstrução de práticas sociais que se realizam ao longo da existência dos sujeitos.

\section{REFERÊNCIAS BIBLIOGRÁFICAS}

BAKHTIN, M. Estética da criação verbal. Tradução Maria Ermantina Galvão G. Pereira. 4. ed. São Paulo: Martins Fontes, 2003.

Hucitec, 2006.

.VOLOCHINOV, V. Marxismo e filosofia da linguagem. 12. ed. São Paulo:

MENEGASSI, R.J. Responsividade e dialogismo no discurso escrito. In: NAVARRO, P. (Org.). O discurso nos domínios da linguagem e da história. São Carlos: Claraluz, 2008, p. 135-148.

. Aspectos da responsividade na interação verbal. Línguas \& Letras. Unioeste, Cascavel/Pr, v. 10, n. 18, p. 147-170, $1^{\circ}$ sem. 2009.

PARANÁ. Secretaria de Estado da Educação. Documento Síntese. Programa de Desenvolvimento Educacional - PDE, 2007.

Secretaria de Estado da Educação. Secretaria da Ciência, Tecnologia e Ensino

Superior. Cadernos PDE 2007: produção didático-pedagógica. Curitiba: SEED, SETI, 2009.

Secretaria de Estado da Educação. Diretrizes Curriculares Estaduais Língua Portuguesa, 2009.

- Secretaria de Estado da Educação. Superintendência de Educação. Coordenação Estadual do PDE. Programa de Desenvolvimento Educacional -PDE. Versão preliminar - 2009.

SILVA, O.H.M. O Programa de Desenvolvimento Educacional do Paraná - PDE/PR. In: IX EDUCERE - Congresso Nacional de Educação - III ENCONTRO SUL BRASILEIRO DE PSICOPEDAGOGIA, 2009, Curitiba/Pr. Anais... Curitiba: Pontifícia Universidade Católica do Paraná, 2009, p. 4251-4264.

VYGOTSKY, L.S. A formação social da mente: o desenvolvimento dos processos psicológicos superiores. São Paulo: Martins Fontes, 2007. 